Portland State University

PDXScholar

$1-1-2011$

\title{
Early Childhood Inclusion: Teacher Perception of the Supports Needed to Fully Include Children with Special Needs
}

Meredith Villines

Portland State University

Follow this and additional works at: https://pdxscholar.library.pdx.edu/open_access_etds Let us know how access to this document benefits you.

Recommended Citation

Villines, Meredith, "Early Childhood Inclusion: Teacher Perception of the Supports Needed to Fully Include Children with Special Needs" (2011). Dissertations and Theses. Paper 425.

https://doi.org/10.15760/etd.425

This Thesis is brought to you for free and open access. It has been accepted for inclusion in Dissertations and Theses by an authorized administrator of PDXScholar. Please contact us if we can make this document more accessible: pdxscholar@pdx.edu. 
Early Childhood Inclusion: Teacher Perception of the Supports Needed to

Fully Include Children with Special Needs

By

Meredith Villines

A thesis submitted in partial fulfillment of the requirements for the degree of

\author{
Master of Science \\ in \\ Special Education
}

Thesis Committee:

Leslie Munson, Chair

David Allen

Ellie Justice

Portland State University 


\begin{abstract}
Inclusion of children with disabilities in early childhood settings remains a goal for many early care and education centers and professionals. In this study, the perceptions of supports needed to accomplish this goal were examined. Early childhood teachers from a university-based child care center, which is inspired by the schools in Reggio Emilia, Italy, were interviewed and asked to explore their feelings and thoughts on fully including children with disabilities in their classrooms. An examination of their perceptions led to the identification of four major themes: a) everyone is valuable in the classroom community, b) additional training is needed, c) support from administrators, peers, specialists, and therapists, d) experience fosters success. From these themes the researcher found that teachers felt support from administrators(staffing, policies and procedures, time for meetings), peers, and on-site consultants, additional training, and an over arching philosophy of accepting differences were crucial to successful inclusion. The participants also indicated that all new teachers, whether in pre-service or through inservice should have access to these supports and be provided with information about the benefits and positive experiences of others who have included a child with a disability into their classroom. This study will add to the continuing discussion of early childhood inclusion and provide additional information for programmatic decision making within a particular setting.
\end{abstract}




\section{Dedication}

I would like to dedicate this to my daughter, Hazel Rose Villines who has inspired me to finish this project and move forward into future endeavors with excitement and a smile. 


\section{Acknowledgements}

I would like to take this opportunity to thank David Allen for all of his support and guidance during my entire Master's program, especially as I composed the following pages. I would also like to thank the other members of my thesis committee, Leslie Munson and Ellie Justice. Without the patience and understanding of these three, I would not have been able to come this far with my research.

I would also like to acknowledge the teachers at Helen Gordon Child Development Center (HGCDC) who welcomed me with open hearts and minds during the 2008-2009 school year as I embarked on a new path in my career. All of the teachers were gracious and helped me to better understand the complexities of inclusion at the center. I would especially like to thank the teachers who agreed to be interviewed for this research project.

Finally, I would like to say thank you to my friends and family who stood by with encouraging words, and an unwavering belief in my ability to complete this project. I am especially thankful to my parents, Beverly and Buddy Villines, and my friends, Bonnie Robbins and Tiffany Scott. 


\section{Table of Contents}

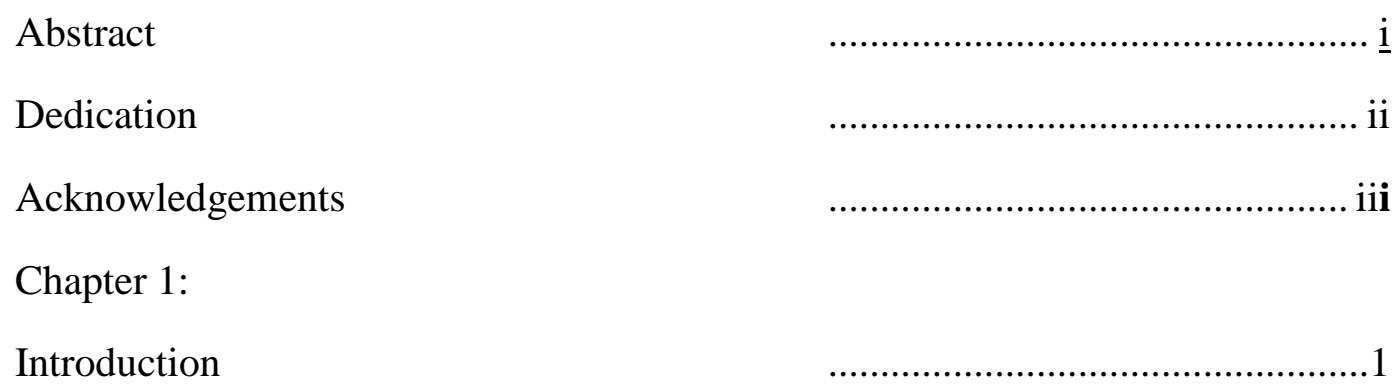

Chapter 2:

Literature Review

Chapter 3:

Research Methods

Chapter 4:

Results

\section{Chapter 5:}

Discussion 48

References 56

Appendices
A. Demographic Information
66
B. Human Subjects Approval Letter
68
C. Semi-Structured Interview Guide
71
D. Reflective Journal 


\section{Chapter 1: Introduction}

Early Childhood Inclusion: Teacher Perception of the Supports Needed to

Fully Include Children with Special Needs

Early Childhood Education is a rapidly changing professional field. Described by Buysee and Wesley (2004) as being divided into three strains: child care, early education, and early intervention, the field is often disconnected professionally (including professional organizations, guidelines, and pre-professional training), and economically (in terms of the populations accessing each strain, funding, and pay scales). Additionally, there are a growing number of children in the United States in early care and education settings (National Association for Childcare Resource\& Referral Agencies, 2009; National Center for Educational Statistics, 2006). Differences across ability, race, and socio-economic status are commonly seen in the same center. With this growth, an increasing number of children with disabilities are being served in typical settings (e.g., child care or early education settings), and professionals are being asked to meet their varying needs (United States Department of Education, 2007). Many professionals in these settings are reporting similar experiences in regards to these increased expectations. They report feeling underprepared, under-supported, and insecure in their ability to provide high quality experiences for all of the children in their care. Despite growing support for early childhood inclusion and a unified definition from the Division of Early Childhood and the National Association for the Education of Young Children (DEC/NAEYC, 2009), barriers remain that prevent children with disabilities from 
participating in early childhood programs around the country. According to researchers, (Bricker, 2000; Dinnebell, McInerney, \& Fox, 1998; Odom, 2000) barriers include the lack of a unified pre-service system for educating early childhood professionals (e.g., early childhood education, early childhood special education), inadequate support for early childhood educators, and associated barriers experienced by those professionals who are asked to provide high quality inclusive early childhood education in their settings. What supports would increase their confidence and competence? Are they the same supports that research and administrators have attempted to provide? Is the delivery of the supports the key to increasing efficacy? Does the school's philosophy or curriculum have an influence on the efficacy of inclusion? This study attempts to answer these questions by examining the experiences of teachers at a university-based school, inspired by the schools in Reggio-Emilia, located in Southwest Portland, OR. These questions are being asked all over the country as states grapple with the challenges of ensuring that even the youngest children with disabilities are being served in the least restrictive environment and have access to programs which serve children who are typically developing.

In the following paragraphs the researcher examines current literature on inclusion in early childhood. The literature examined includes a review of the legal basis for inclusion in the United States, definitions of inclusion in early childhood, teacher's perceptions of inclusion, administrative supports needed to support inclusion, specialized training and education, and the influence of curriculum and philosophy on inclusive practices. 


\section{Chapter 2: Literature Review}

\section{Legal Basis for Inclusion in the United States}

Several legislative acts created a path for the inclusion of infants, toddlers, and preschool children in the general early care and education settings in the United States. As early as 1968, Public Law (P.L.) 90-538, the Handicapped Children's Early Education Assistance Act provided funding to states for the development, evaluation and refinement of model demonstration programs to serve eligible infants, preschool children, and their families (Garguilio \& Kilgo, 2005; Meisels \& Shonkoff, 2000; United States Department of Education, Office of Special Education Programs, 2009). This legislation led to the development of program models such as Project Head Start and the Carolina Abecedarian Project which served children and families from low socio-economic backgrounds. In 1972 (P.L. 92-424), amendments were added to mandate Head Start programs to reserve $10 \%$ of enrollment for children with disabilities. These early projects created a framework for intervention in at-risk populations and provided data to support the development of high quality early childhood programs for all children under age five (Garguilio \& Kilgo, 2005).

In 1973, the Rehabilitation Act was passed and declared that a person shall not be discriminated against based on disability within public and private programs which receive federal funding (Title 34 Department of Education, 2009). This act, while not providing funding to programs, established precedent for the right to free, appropriate, public education (FAPE). Later, P.L. 94-142, the Education for All Handicapped 
Children Act (1975), mandated the principle of FAPE, and articulated requirements for the Individualized Education Plan (IEP) to be carried out in the least restrictive environment (LRE). Mandates for LRE require that children be served, to the greatest extent possible, in environments including children with and without disabilities. Further amendments to the Education for All Handicapped Act, in 1986 (P.L. 99-457), extended protections of the right to FAPE to children with disabilities under five years of age. In 1986, the Education for All Handicapped Children Act was reauthorized as P.L. 99-457 and resulted in the act being renamed Individuals with Disabilities Education Act or IDEA in 1990. IDEA was instrumental in promoting early intervention services for children under three through funding incentives, and in mandating all states provide FAPE to children three to twenty-one. Later reauthorizations of IDEA (P.L. 101-476, P.L. 105-17, IDEA 1997, and IDEIA 2004) further clarified provisions for placement in natural and least restrictive environments (United States Department of Education, Office of Special Education and Rehabilitative Service, 2009). IDEIA 2004 currently guides policy and practice in the field of early childhood special education. However, the law does not provide a legal definition, thus creating challenges for states that are attempting to meet LRE requirements.

The Americans with Disabilities Act (ADA), a civil rights law that further protects persons with disabilities against discrimination in employment, provides federal requirements for accessibility, accommodations in transportation, environment, and telecommunications in public and private institutions, businesses, schools, and child care facilities (ADA, 1990). Subsequent revisions of this law expanded protections for 
children with disabilities to private early care and education programs, encouraging these programs to develop policies and systems to support all children (Wood \& Youcha, 2009).

\section{Inclusion}

The topic of including children with disabilities in general early childhood programs has been defined and discussed in educational literature since the $1970 \mathrm{~s}$ (Bricker, 1978; Bricker \& Bricker, 1971; Guralnick, 1976). Within the literature, however, are several different terms used interchangeably to describe this activity. Terms such as mainstreaming, integration, least restrictive environment, and inclusion are most often used to describe the same thing but upon further analysis are actually very different. This led to confusion and conflict in professional circles and within debates for school reform.

Ryndak, Jackson, and Billingsley (2000) examined different writings and interviewed the top experts to gain a better understanding of what inclusion means for students with moderate to severe disabilities. Participants in this study were considered experts if they were authors or editors of relevant literature. The experts were asked to present their definition of inclusion. Seven themes that described inclusive education for this population of students emerged including 1) placement in a natural typical setting; 2) all students together for instruction and learning; 3 ) supports and modification within general education curriculum; 4) belongingness, equal membership and acceptance; 5) collaborative integrated services; 6) a systematic philosophy; 7) and a meshing of general 
and special education systems into one. So, is inclusion about placement or the philosophy? This study and others suggest it may be about both.

Currently, there is no federal definition of inclusion included in the law. The law instead calls for placement in the least restrictive environment, which means to the maximum extent appropriate, children with disabilities, are to be educated with children who are nondisabled (IDEA, 1997). Groups such as the DEC, NAEYC, and many leading researchers have developed definitions. In April 2009, a joint position statement, was issued by the DEC and NAEYC stating that early childhood inclusion "embodies the values, policies, and practices that support the right of every infant and young child and his or her family, regardless of ability, to participate in a broad range of activities and contexts as full members of families, communities, and society" (p 2). The intent of the statement was to define inclusion for practitioners, families, and the public, and offer guidance based on three principles: 1) access, 2) participation, and 3) support. For the purposes of this study, this definition will be used when discussing inclusion.

\section{Teacher Perceptions of Inclusion}

Examinations of teacher's perceptions of inclusion in early childhood settings suggest many early childhood teachers have positive perceptions about inclusion with this age group (Leatherman, 2007; Mulvihill, Shearer, \& Van Horn, 2002; Smith \& Diugosh, 1999; Smith \& Smith, 2000). Despite this, in 2005, only 34\% of children three to five years old in the 50 states and the District of Columbia who were receiving services under Part B of IDEA were served in early childhood settings (IDEA, 2006). The reasons 
for this are complex and vary across states. Review of the current literature on inclusion in early childhood attributes the discrepancy between research and practice to several factors including 1) inconsistencies in leadership, 2) lack of specialized training; 3) differences in experience; 4) differing perceptions of inclusion; and 5) attitudes among teachers to be major barriers (Bricker, 2000; Dinnebell, et al., 1998; Odom, 2000). This is reflected in a study by Dinnebell, et al. (1998) of teachers from a Northwest Ohio childcare resource and referral network. The researchers used surveys to collect information regarding the inclusion of children with disabilities. Results indicated $70 \%$ of respondents believed lack of knowledge regarding disabilities and how to provide instruction to children with disabilities to be a barrier to providing care, $29 \%$ indicated a lack of confidence, $9 \%$ did not enjoy working with young children with special needs and their families, and $4 \%$ did not believe young children with special needs should be in the same classroom with children who are typically developing. With respect to inclusion, changing attitudes and increased opportunities for professional development lead to an increase in opportunities given to children with disabilities (Mulvihill, et al., 2002; Ryandak, et al., 2000).

\section{Administrative Support}

One common theme found in the literature is the need for strong administrative support. Administrative support can take many forms. An administrator's positive attitude towards inclusion was most often referenced (Capper, Frattura, \& Keyes, 2000; Leatherman, 2007; Mulvihill, 2006; Riehl, 2000; Smith \& Diugosh, L., 1999; Smith \& Smith, 2000; Stainback, Stainback, \& Forest, 1989; VanHorn, Burrello, \& DeClue, 
1992). Other social science research indicates the need for positive attitudes to facilitate social change. In essence, the administrators set the tone for the entire program. If an administrator believes in the broader concepts of inclusion as being beneficial for all children, an extension of anti-bias teaching, a move towards equality in society, and communicates those beliefs to staff and parents, teachers will not have to carry so much of the weight for justifying inclusion within the program (Sapon-Shevin, 2003; Smith, 1999).

Through policies and procedures, administrators are able establish systems that will support teachers in their classrooms, and lay a foundation for understanding among teachers and families enrolled in the program. This extends to families of children who are typically developing who believe that including a child with disabilities in the classroom will take away from their child's educational experience. With knowledge of current research and evidence on the benefits of inclusion for children with and without disabilities an administrator can reframe parents concerns and provide education and information (Wolery \& Wilbers, 1994; Wolery \& Odom, 2000). This role is often hard to fill because many administrators do not feel they have the experience, knowledge, or access to current research on the benefits or reality of having a fully inclusive program (Leatherman, 2007; Wolery \& Odom, 2000). Other ways administrators can support teachers involve providing additional funds for materials, adding additional staff to the classroom to lower child-to-staff ratios, and providing time for planning for individualized instruction, consultation, and collaborative team meetings (Wolery \& Wilbers, 1994). 


\section{Specialized Training/Education}

Also, noted to be a considerable barrier to successful inclusion, is the lack of specialized training (Bricker, 2000; Mulvilhill, et al., 2002; Soodak, Erwin, Winton, Brotherson, Hanson, \& Brault, 2002; Wolery \& Odom, 2000; Wolery \& Wilbers, 1994). Early childhood teachers need to have training in teaching individualized goals within activities, individualized instruction, and progress monitoring (Bricker, 2000; Wolery, 2007). Many early childhood educators believe that this training is not adequately covered in pre-service programs or in-service training (Dinnebell, et al., 1998). Teachers also report an increased level of confidence when additional training is acquired, thus leading to positive outcomes for children in their classrooms. Teachers who had additional training reported fewer needs and perceived barriers to inclusion (Mulvihill, et al., 2002). One can thus infer that the more education the teacher has, the more successful the program will be at including a child with a disability.

\section{Influence of Program Philosophy and Curriculum}

Very little research has examined the influence of program philosophy or curriculum as it relates to providing support for children with disabilities. At the particular university-based preschool where this research occurred, three two major components build or support the program philosophy. The early childhood program at Helen Gordon Child Development Center is influenced by the municipal preschools in Reggio Emilia, Italy and references Anti-Bias Curriculum to support the learning of all young children in the school. Additionally, in the infant-toddler program, the teachers are 
influenced by the teaching of Magda Gerber and the Resources for Infant Educarers

(RIE) to support the development of the youngest learners in the program.

\section{Reggio and Inclusion}

In December 1991, an article in Newsweek highlighting the best schools in the world introduced the greater American public to the municipal preschools in Reggio Emilia, Italy (Wingert \& Kantrowitz, 1991). Although the description was brief and understated, the important influence of these schools as models of high quality on early education was far reaching. Today one can find "Reggio-Inspired" schools, or groups of professionals who study the practices of the schools in Reggio Emilia, in forty-seven of the fifty states (North American Reggio Emilia Alliance, 2010). There are no clear definitions about what it means to be "Reggio Inspired" found in the literature other than what the term implies, to be inspired by the schools of Reggio Emilia and the practices found there. With the growth of schools inspired by studying the Reggio Approach, collaboration and dialogue among practitioners and researchers in the United States, Canada and Mexico has prompted the development of the North American Reggio Exchange Alliance (NAREA). This organization disseminates information related to the experiences of teachers in North America who are inspired by the Reggio Approach, provides opportunities for professional development, coordinates dialogue between teachers in Italy and in North America, and provides a historical context and links related to schools in Reggio Emilia and the Reggio Approach. 
Loris Malaguzi was instrumental in developing the Reggio Approach as he led the school, municipality, families, and teachers in pedagogical discussions for over thirty years. His most referenced text describes what he calls "the hundred languages of children." In 1993, following an increased interest nationally and internationally, Malaguzzi and other educators in Italy and North America published a compilation of articles, explorations and reflections known as The Hundred Languages of Children. Within this book and in other articles, it can be seen that the approach to childhood did not originate with the first school in 1945, but was carefully cultured over a number of years during conflict, discussion, discovery, and the careful study of children and learning during childhood (Edward, Gandini, \& Forman, 1993). So, what is the Reggio Approach? Gandini (2008) describes the approach as one richly routed in parent involvement, focused on an image of the child as competent and full of potential, and in which the child is viewed in the context of the relationships they have within different systems. The child is also viewed as a partner in learning with the teacher. In this relationship, there is value placed on the role of the environment to inspire and provide opportunities for learning. The Reggio Approach places importance on projects and the expressive arts as a means of communicating the experiences, theories, and ideas of the child (Katz, 1993). All of these elements are captured and explored through the use of documentation. The teachers use a variety of methods (recording, photographing, writing, and drawing) to document the children's work and to provide evidence to support the theories developed by the group or images of learning supported by research (Edwards, Gandini, \& Forman, 1998; Katz, 1998; Rinaldi, 1998). 
Another unique feature to the schools, rooted in the image of the child, is the precedence the schools have set for fully including children with special needs, or special rights as they are referred to by the educators in Reggio Emilia. Since the inception of the first schools under the municipality in 1963, there has been a priority given to children with disabilities and children of single parents. In 1971 and 1977, the Italian Parliament validated this practice by enacting the first law governing the education of children with disabilities, which established the right to desegregated education of children in public schools (Smith, 1998). In the municipal preschools, the number of children with special rights is limited to one to two per class of twenty children with two teachers. In some cases, an additional teacher is added to the group so that all children receive adequate support in their learning experiences (Smith, 1998). A value is placed upon the differences that these children bring to the classroom and much thought, care, and collaboration is built around supporting individual development and also around understanding what the child can uniquely offer and teach the group (Edwards, et al., 1998; Gandini \& Kaminsky, 2006). This explicit value of differences provides a unique foundation for the success of full inclusion at these schools. A psychologist is included in the team of pedagogical coordinators to provide training, support, and coordination of services for all children within the municipal preschools. By coordinating efforts, specialists work with the teachers and parents at the schools and provide support and coconstruct ways of providing support for the child with special rights. When asked how she provides support for classroom teachers and staff working with children with special rights, psychologist Ivana Soncini impresses the importance of sharing information with all the staff at the center so that everyone feels comfortable and confident in working 
with the child (Gandini \& Kaminsky, 2006). Additionally, in-service training related to self-observation (using video recordings and reflecting upon it with the group) and selfreflection are the most effective way of examining the teacher's practice in relation to the child with special rights. Using video recordings, the teachers and staff examine the reactions the child has to interactions with the teacher and other children. Specialists within the municipality also come into work with individual children in the schools and support teachers as they learn more about the child. This process of bringing everyone in the life of the child together to explore their identity and learning in the school creates a network of support and community for the family of the child with a disability as well (Smith, 1998).

Little has been written about how North American schools which ascribe to the Reggio Approach have integrated this aspect of the view of the child. In a search of articles on "Reggio-Inspired" schools and inclusion only two actually spoke to the practice of inclusion within "Reggio-Inspired" schools in the United States. One of the articles by Nora Thompson, a teacher at Galileo Early Childhood Center in Mason, Michigan (2006) reflects upon the adoption of the phrase "child with special rights" as an important and intentional shift in the thinking of the school and its teachers. With the difference in semantics, a conveyed meaning of ability instead of need was communicated to the staff and families at the center. Additionally, policies were established so that there was an expectation on behalf of teachers, staff, parents, that specialists working with children at the center would always provide the services in the classrooms and when possible with other children. This practice coincides with research 
in early intervention regarding best practice and embedding interventions within the context of routines. In conversations with practitioners in Oregon, similar experiences have been found. One director conveyed that the image of the child as capable and full of potential, as well as the relationship between the teacher, child, and other children as coconstructors of knowledge within the system of the classroom/school provided a solid foundation for inclusion to be possible in their school (E. Justice, personal communication, September 15, 2009).

In the United States, there are many different models for including a child with a disability in early education. In many ways, early childhood providers and researchers are still learning and experimenting with different models. For those who believe that all children have the right to quality early care and education, much can be learned from the schools in Reggio Emilia. The rich history of community and municipal support has made these schools possible by providing funding, space, and a dialogue around the importance of childhood. The children's work in Reggio is taken seriously and often displayed in large museums of the city or in the town square. For schools in the United States, these changes can seem daunting, but the shift from a deficit model to one where children are viewed as fully capable members of the group is a most important starting point. When this researcher traveled to Reggio Emilia in April, 2008, many of my American counterparts expressed that these schools represented an impossible dream. However, it was put best by an Italian parent, "Is it a dream? A utopia? Without dreams and utopias, the 'new' is never invented (as cited in Smith, 2008)." 


\section{Anti-Bias Curriculum and Inclusion}

In 1987, Derman-Sparks and her colleagues on the ABC task force defined and developed a curriculum which at the time was viewed as revolutionary. The premise was that all children have the right to be fully appreciated in their community, to be celebrated for who they are, and to be empowered to ask honest questions about difference and advocate for the acceptance of difference in the world. The text was intended to provide guidance for teachers who worked with young children. Not a curriculum in the traditional sense where one might find activities organized across months or seasons, Anti-Bias curriculum challenged teachers to develop activities, create environments, and support a better understanding of difference across race, ethnicity, religion, culture, family systems, and ability throughout the year. Based on a developmental approach, questions about difference are addressed on a case by case basis, and are guided by the child's specific interests or concerns. Unlike other multi-cultural curricula this challenge did not encourage teachers to take a "drive-by" model to learning about others from backgrounds different from the dominate culture. The belief being that these curricula make other groups seem unusual or counter to the dominate culture which places them in a position of inferiority, instead of existing on an equal plane with the dominate culture (Derman-Sparks \& Edwards, 2010). In the follow-up second edition, Anti-Bias Education for Young Children and Ourselves (Derman-Sparks \& Edwards, 2010), the dominant group in the United States is defined as those with the greatest power, privilege, and social status ( historically being white, Christian, affluent, and male); thus, dominant culture being the way of life defined by the dominant group as normal and right. 
Several strategies are laid out in both texts regarding implementation of Anti-Bias Curriculum. Many of the suggestions regarding implementation involve environmental modification, changes in language used in the classroom, or the blending of several different instructional strategies to address the learning needs of all children in the classroom. For example, some strategies for reducing bias against people with disabilities include having books or other print materials which discuss, or highlight disability and positive images of persons with disabilities in the community. Also, teachers can include materials such as differently-abled dolls in dramatic play, modified equipment or supplies in different areas of the classroom, and be open and honest when questions arise regarding person with a disability (whether the disability is obvious, such as cerebral palsy or less obvious, like Autism Spectrum Disorders).

Very little research, outside of the original texts, addresses the use of anti-bias curriculum in working with young children with disabilities. The majority of the current research wherein anti-bias curriculum is cited focuses on anti-racism education and combating biases against people of color, people who identify themselves as gay, lesbian, and transgendered and their families. In a search for articles examining the use of antibias curricula and working with children with disabilities, no articles were found or any other citations outside of the chapters found in the first and second editions of the curricula. 


\section{Resources for Infant Educarer (RIE)}

Resources for Infant Educarers, otherwise known as RIE, is a non-profit organization founded by Magda Gerber and Tom Forrest at the Palo Alto Demonstration Infant Program in 1978 (Ade-Ridder, 1989). In order to foster quality care RIE encourages: 1) Basic trust in the child to be an initiator, an explorer and a self learner, 2) An environment for the child that is physically safe, cognitively challenging and emotionally nurturing, 3) Time for uninterrupted play, 4) Freedom to explore and interact with other infants, 5) Involvement of the child in all care activities to allow the child to become an active participant rather than a passive recipient, 6) Sensitive observation of the child in order to understand his/her needs, 7) Consistency, and clearly defined limits and expectations to develop discipline ("Pikler principles," n.d.). The RIE approach is influenced directly by the practices and theories on infant care espoused by Emmi Pikler. Pikler and Gerber worked closely together in Budapest, developing systems of care for institutional childcare facilities. At these facilities there were a variety of infants and children being seen. The two women found that if you nurture a culture of respect for infants and have them participate as much as possible in their care then you will have authentic infants who are: competent, confident, curious, attentive, exploring, cooperative, secure, peaceful, focused, self-initiating, resourceful, involved, cheerful, aware, interested, and inner-directed ("RIE Approach," n.d.; Infant Wing Guidelines, 2008).

In a search for literature on RIE and children with disabilities, no sources were found. The information gathered from the Pikler website inferred this approach as 
appropriate for you children with disabilities, but did not offer any specific guidance for children with disabilities. Likewise, not specific reference to RIE and infants with disabilities was found in the interviews or journals. Thus, the researcher did not cite or use information gathered about RIE in this study.

Implementation of inclusion in early childhood is complex, filled with opportunities and barriers. The purpose of this study was not to examine all of the associated barriers to inclusion in early childhood, but rather to examine the need for support as perceived by teachers at a university-based early childhood center in Portland, Oregon. Through this study, key questions about what supports are needed for early childhood teachers at the center to fully include children with disabilities, and what factors influence their ability to incorporate children with disabilities in their classrooms were addressed. Additionally, the question of program philosophy and curriculum and its influence on teacher efficacy in an inclusive setting was examined. This study added to the continuing discussion of early childhood inclusion and provided additional information for programmatic decision making within a particular setting. 


\section{Chapter 3: Research Methods}

The following section describes the study's participants, the setting, and safeguards taken for human subjects, the measures, procedures, and data analysis. Using a qualitative design, the researcher attempted to better understand needs for support and perceptions of given support when fully including a child with special needs at an urban, university-based preschool in the Northwest.

\section{Research Questions}

The study's research questions were as follows:

1. What supports are needed for early childhood teachers to fully include children with special needs?

2. What are teacher's perceptions of support (e.g., what supports do they perceive to be most helpful and why?)?

3. How does the early childhood teacher's perception of support influence the ability to feel successful in including a child with special needs?

4. How do early childhood teachers perceive successful inclusion of a child with special needs?

5. How does the program philosophy and curriculum influence teachers' ability to fully include a child with a disability? 


\section{Participants}

The participants in this study were purposefully selected from among 25 teachers working at a university-based early care and learning center. Criteria for consideration included the participant's position (lead teacher), whether or not they have had experience with a child with special needs as a part of their classroom, and whether or not they have made formal requests in the last year for support. The sample was limited to six lead teachers, selected amongst ten lead teachers at the center.

Teachers at the center were asked to fill out a demographic information form created by the researcher. Of the six teachers who met the criteria mentioned above, one teacher declined and one teacher withdrew from the study due to conflicts in her schedule and other work related obligations. There were four teachers who participated in interviews and used journals over a six week period to reflect on their experiences including a child with special needs in their classroom. Of the four teachers, one taught in the infant/toddler wing of the school, two taught children ages two to three years old, and one taught preschool-aged children.

\section{Setting}

Research was conducted at a university-based early care and education center located in downtown Portland, Oregon, on the edge of the Portland State University campus. The center is a full-day early care and education program, with infant/toddler, preschool, and kindergarten classrooms. Established in 1971 by a group of young mothers, Helen Gordon Child Development Center (HGCDC) has grown and expanded 
in its current location at $12^{\text {th }}$ and Market Streets in southwest Portland. There are three infant/toddler classrooms (six months to 2 years), three transition classrooms (two to three), and five preschool classrooms (four mixed age, and one four year old preschool classroom), as well as a full day kindergarten. In addition to providing quality early care and education, the center acts as a laboratory setting for students and faculty engaged in research, class assignments, and practicum/student teaching in Early Childhood Education (ECE) and related fields including Psychology, Elementary Education, Special Education, and Speech/Communication.

The philosophies and approach to early childhood education are informed by the infant/toddler and preschool centers in Reggio Emilia, Italy, Anti-Bias Curriculum, and Resources in Infant Educarer (RIE). These curricula are both emergent and constructivist and support children at every stage of development. Evidence-based practices are used to support the growth and development of every child enrolled at the center.

The center is open to children whose parents are either enrolled in university classes, or who are a part of the staff and faculty at the university. There are also placements for children from the general Portland community. However, these spots are limited and are decided based on a waiting list which includes more than 300 families at any given time during the year. In 2000, the program was fully accredited by the National Association for the Education of Young Children (NAEYC). Today, HGCDC continues as a model of excellence in early care and education in the Portland area and surrounding communities. 
Since its inception, Helen Gordon Child Development center has attempted to offer care to the wider campus community (E. Justice, personal communication, February $15,2011)$. In doing so, there has been a history of enrolling children with special needs as the need arose within that setting. This enrollment has not been intentional nor has the school sought out or advertised placements for children with special needs. According to the current director, there has always been at least one student per year with an identified disability enrolled, although there is no documentation to validate this claim (E. Justice, personal communication, February 15, 2011). From her recollection there have been children with Down syndrome, children with Cerebral Palsy, children with Autism Spectrum Disorder (mostly high functioning), and children with mental health or emotional challenges enrolled at the center in the past. Over the last three to five years, there has been an increase in the number of children enrolled who have been identified as having Autism Spectrum Disorder or challenging behaviors (E. Justice, personal communication, February 15, 2011). This has lead to an increase in the need for supports at the centers for teachers, children, and families. Currently, there are no records which provide specific information regarding enrollment of children with disabilities and the supports they receive at the school.

In 2001, there began a collaborative partnership with the Graduate School of Education to provide funding for a graduate assistant or intern from the Department of Special Education's Early Intervention/Early Childhood Special Education program. From 2001-2004, a graduate assistant was placed at Helen Gordon Child Development Center to support the needs of children with disabilities and facilitate the principles of 
inclusion at the school. The role of this graduate assistant was to provide support to teachers in and out of the classroom in a consultative role, providing teachers with information and resources about young children with disabilities, and extend support to children and families directly as needed (E. Justice, personal communication, February 15, 2011). According to the director (E. Justice, personal communication, February 15,2011), the main activities of this graduate student were creating and updating resource binders for teachers to access if they needed more information on a child with a disability. No records regarding the activities of the graduate student could be located at the time of the study. From 2004 to 2008, there was not a graduate assistant from the Graduate School of Education due to lack of funding and the involvement of HGCDC in other activities, such as expansion and study groups to Reggio Emilia, Italy (E. Justice, personal communication, February 15, 2011).

In 2008, funding was again acquired and priority placed on inclusion of children with disabilities and supporting those children within the center (E. Justice, personal communication, February 15, 2011). Since this time, the graduate assistant or intern has been involved in the creation and implementation of more systematic supports for teachers, children, and families. Those supports include the more consistent use of the Ages and Stages Questionnaire (ASQ), a developmental screening, and the ASQSocial/Emotional screening. The graduate student is responsible for organizing training related to this screening, scoring the screening, and providing feedback or resources to teachers if a delay is indicated. Additionally, the graduate student works in conjunction with the director to organize and facilitate meetings of the Child Study Team, which was 
developed in 2008 and works with teachers to support children with special needs in the classroom and determine whether further evaluation is needed. The Child Study Team is made up of members of the special education faculty, a member from the administrative team at the school, and teachers from each age group. Teachers can bring concerns about a child to the Child Study Team during their monthly meetings, and receive support in the form of observations, ideas for change, and feedback from outside parties. Currently, research is being conducted to measure the efficacy of this process and its influence on the successful inclusion of children with disabilities at the school. Other responsibilities of the graduate student include providing support within the classroom, as well as in a consultative role, updating resource binders, and developing/maintaining a resource library for teachers at the school, and collecting data related to ongoing activities and individualized goals. (i.e., interventions recommended by Child Study Team or Special Educators)

\section{Measures}

Qualitative data were collected using a variety of measures including a demographic information form, a semi-structured interview guide, and a guide for reflective journals. Information regarding the participant's professional development over the last year was also collected from their personnel records. This information, however, was not used during data analysis because it was revealed by participants in the interviews. The demographic information form, created by the researcher, provided information regarding education level, years of experience teaching, and experience with children with special needs. This form can be found in Appendix A. Central to the study 
was the collection of information through semi-structured interviews. Semi-structured interviews consist of a fairly open framework, which allows the researcher to ask focused, yet open-ended questions (Patton, 2003). This method of interviewing allows for two-way conversation to occur between researcher and participant. Not all questions are designed ahead of time, and many occur spontaneously during the interview based on the participant's response. The researcher reserves the right to ask follow-up questions based on the participant's answers. A focused guide is necessary to ensure inquiries are related to the research questions. The benefit of using this type of interview structure is the respondent's ability to discuss a topic openly and at length, occasionally revealing truths as the process continues. The semi-structured interview guide was developed by the researcher and can be found in the Appendix C.

The interviews were conducted at the center, in a conference room with few distractions and interruptions, during a time which was convenient for the interviewee. Due to scheduling conflicts, one interview was conducted outside the center in a public space. All of the interviews were recorded using a digital recording device. The recorded interviews were then transcribed by the researcher using a speech recognition software program, Dragon Naturally Speaking. To ensure accuracy, the interviews were reviewed by the researcher for mistakes. The researcher then returned the transcribed interviews to the participant for an additional review to ensure accuracy and validity of the measure. This process also allowed the participant to clarify any points and reflect upon responses further. The participants were permitted to make changes or additions as necessary. The researcher was the only person to review and analyze data collected from interviews. 
In addition to interviews, each teacher was provided a small journal to write weekly reflections for six weeks on their experiences working in classrooms with children with special needs. Questions, proposed by the researcher, were provided as prompts for the reflections. These journals provided additional information to support the interviews. Journals allowed the participant time and space to reflect openly about their experiences without the pressure to respond directly to another person. The researcher collected the journals at the end of the study, prior to data analysis. Suggested journal topics can be found in Appendix D.

\section{Procedures}

During the first week of the study, a demographic information form was delivered to staff at the center by the researcher. Participants were selected following the completion of the demographic information form. Criteria for consideration included the participant's position (lead teacher), whether or not they have had experience with a child with special needs as a part of their classroom, and whether or not they indicated a need for support to include a child with special needs during the 2008-2009 school year. Participants were notified at the end of the second week of research, and asked to complete consent forms developed for the Human Subjects Research Review Committee (HSRRC) to ensure safeguards for human subjects. These safeguards include informed consent, the ability to withdraw from the study at anytime, and information as to where to address concerns. Once participants consented to take part in the study, the researcher assigned codes (e.g. Teacher A, B, C...) to protect the identity of participants, and then scheduled a time for the first interview. All interviews occurred during a time that was 
convenient to the participant and were recorded using a digital recording device.

Interviews were transcribed verbatim using speech recognition software. Interviews were transcribed within two weeks from the time the interview was completed. The timeline for completion of interviews was six weeks. During this time, the participants were provided journals and a guide for reflections. These journals were collected following completion and transcription of interviews during the sixth week.

An important factor in the ability to conduct research at a particular setting is the researcher's level of participation. Prior to and at the beginning of this study the researcher was able to act as a participant observer. A participant observer is one who makes observations as a part of and participant in the setting being observed (Gay, Mills \& Airasian, 2009). The researcher entered the setting in 2008 as a graduate assistant to support teachers, students, and staff so they could fully include children with special needs in the program. At that time, conversations with the center's director indicated that with the increase of children with disabilities in the program there was an increased need for support. This support was needed not only for the children but also for the teachers. The intent was to provide staff and teachers with support so that they could feel more secure in providing high quality early education experiences for all of the children enrolled, especially those with different learning needs. At the beginning of this project, the researcher worked with staff, administration, and faculty members to develop strategies to effectively include children with special needs in the program and plan for the next year. 
As the research continued, the researcher's role changed and presence at the center was less frequent if not at all. Work included consulting directly with teachers, working 1:1 with students with special needs, developing resource materials for staff, and arranging professional development activities for the topic of inclusion, referral, and early intervention/early childhood special education. Relationships developed during this process that may have had potential to create bias in the research. To protect against bias multiple sources of information were collected and triangulated to ensure trustworthiness.

\section{Safeguards for Humans Subjects}

The researcher reviewed all the requirements of the University to safeguard against unethical treatment of human subjects. The University's Human Subjects Research Review Committee (HSRRC) provides independent determinations on methods, risks, benefits and rights involved in research involving human subjects. These safeguards included ensuring the protection of all participants' identity by withdrawing any identifying information from the research results. Consent was obtained to use information gathered from interviews, professional development plans, field notes, and journal entries. Application for approval of research took place prior to beginning the research. During the initial stages of the research, each teacher received a code to protect identity. All information regarding teachers' responses was kept confidential and in a location outside the center. 


\section{Data Collection}

Data were collected from participants in a variety of ways, including interviews, journals, demographic and professional development information. The collection of this data occurred in three stages. During the initial stage, demographic information was collected and used to determine participants. Once participants were selected, information regarding experience and level of education, gathered from this measure, was examined during the analysis stage to make inferences about the level of education or experience as it relates to feelings of success in including children with disabilities. Current research indicates level of education and experience is a factor in the successful inclusion of children with disabilities (Odom, 2000; Wolery \& Odom, 2000; Wolery and Wilbers, 1994; Wolery, 2007).

During the second stage of data collection, semi-structured interviews with selected participants were conducted at the center. The majority of the data came from this source. Interviews were recorded and transcribed verbatim, then given to the participant to perform a member check. A member check is a way to assure the findings are recognizable and accurate to the participant. This process ensured that any recorded information is reliable and valid. Professional development records of participants were also collected during this stage of data collection. Professional development records were not used in the data analysis process, but were merely there to confirm or reject information collected during the interviews related to professional development. 
The third and final stage of data collection included the review and dissemination of field notes and reflective journals. While participants were expected to keep journals throughout the study, the information within the journals was not reviewed until the interview process was completed.

\section{Data Analysis}

During each stage of data collection, the researcher read and reread the interviews, then identified codes, or small pieces of relevant information. Simultaneously, information from the journals was read and reread and coded. The codes then were written on cards that were laid out, examined, and analyzed. From these codes the researcher was better able to determine common themes across different sources of data (i.e. Case A, B, or C). This process, known as content analysis, allows the researcher to organize qualitative data into thematic units of information (Patton, 2002). When themes are established, the researcher may examine evidence to build on those themes from the remaining sources of data. These themes guided the researcher in drawing conclusions about the research questions, and disseminating it in a meaningful and constructive way. Discussion with an outside party regarding the codes took place during the development of codes, however, no outside party reviewed the information from journals or interviews to determine consensus.

When teachers received their interviews to review, they did not provide feedback or expand on their statements, other than providing grammatical clarification. Also, while the journals provided some information to triangulate with the interviews, they did not 
provide the researcher with a substantial amount of data. Thus, the majority of the information revealed in the results section is derived from the interviews. 


\section{Chapter 4: Results}

This study focused on the supports necessary for early childhood educators to fully include children with disabilities in their classrooms. Themes were identified through data analysis to answer research questions: 1) What supports are needed for early childhood teachers to fully include children with special needs? 2) What are teacher's perceptions of support (e.g., what supports do they perceive to be most helpful and why)?

3) How does the early childhood teacher's perception of support influence their ability to feel successful in including a child with special needs? 4) How do early childhood teachers perceive successful inclusion of a child with special needs? 5) How does the program philosophy and curriculum influence teachers' ability to fully include a child with a disability? While all of the questions were not fully addressed by participants, the following paragraphs reflect the major points of such analysis.

\section{Research Question \#1}

The reflections on this particular question were multi-faceted, incorporating multiple themes including training, support for peers, administrators, and specialists, and relying on one's experience and self-sufficiency in seeking knowledge. In the following paragraphs, three themes are presented in an attempt to answer the overarching question of what supports are necessary for a teacher to fully include a child with special needs.

\section{Additional Training}

First, the theme of additional training, as an answer to research question one, will be examined. Throughout the interviews, there was a pervasive opinion expressed by the 
teachers interviewed that more training was needed to secure feelings of efficacy in the school and classroom. This is despite the fact that all of the teachers interviewed had some level of experience in higher education- all had a bachelor's degree in a related field, and three of the four had completed a Master's Degree in Curriculum and Instruction with an Early Childhood Specialization, with one teacher enrolled in the same Master's program. During their education, none of the teacher's has received specific training related to working with children with special needs other than a few in-service trainings provided by HGCDC or the local Childcare Resource and Referral Service. This was confirmed by examining the professional development records at kept at the center for continued licensure. Examples from each interview indicated that professional development in inclusive curriculum and instruction, collaboration and consultation, disability specific information, and identification, referral, and resources related to inclusion were critical if inclusion was to be successful. These aspects of the theme reflect a belief that professional development is an important aspect of the supports teachers need to fully include children with disabilities. The following is an examination of the different points teachers at this particular school believe to be important in identifying needs for professional development.

When discussing programmatic needs for fostering and supporting a more inclusive school and staff, those interviewed believed that additional training was needed. One teacher explained that despite having a degree in early childhood and being enrolled in a Master's Program specializing in Curriculum and Instruction with a focus in Early Childhood Education, she often felt unprepared and lacked in the knowledge or 
experience needed to fully include a child with a disability in the classroom. Much of the information and training she does have related to working with children with special needs has came from her independent research, "brought on by a child in my class that I have concerns about." The other teachers explained that they too gathered most of their information related to disabilities in early childhood from independent research. Teacher C stated,

...for me, when I've found or had children in my classes that's why I've taken all those courses. You know even if they're just the weekend ones where you have a child that's extremely shy so I go and find every book I can find on how do you deal with children that are extremely shy or really extroverted to the point where they are into people's faces or are really introverts. Whatever the issue is, I spent a lot of time on my own. So that's one... One is independent study

Those interviewed felt that having more "opportunities for professional development in that realm would definitely help just having the teachers' just keeping current with all the information that is out there." One teacher declared, "I think it's an essential piece that everyone needs to have a background in or some kind of training or understanding, some knowledge about... whether you have a child in your classroom or not." This teacher added,

I think that more teachers need to have training since I'm noticing an increase in children with special needs coming in, not just into our center but in schools in general. I think it's an essential piece that everyone needs to have a background in 
or some kind of training or understanding, some knowledge about... whether you have a child in your classroom or not.

In addition to professional development related to working with children with disabilities, the teachers also felt that there needed to be more professional development opportunities for teachers related to collaboration and working with parents of children with special needs. One area brought up by a younger teacher was training around identification and communicating with parents when one has a concern, stating directly, "I think more professional development opportunities that are specifically geared toward working with families and children with special needs." The teacher described two experiences wherein she has had difficulties approaching parents when she knew there was a difference in the child's development.

She described one experience,

I think one of the challenges...I had one family that at the beginning of the year we noticed some concerns with language and comprehension a little bit and brought that up to the parents and they had similar concerns but their biggest fear was "my child is going to be labeled" and they were like, "I don't want to have my child assessed right now... But this was a child that when you tried to communicate would just repeat random things or had an amazing memory so would recite something that she had seen or was in a book but nothing in the moment it was never spontaneous speech. So, we went back to the parents again with the observations- we had a coordinator come in and some other teachers just 
to observe and plus our own observations and I think we did that for a whole other term ... We were all feeling that it was... nothing had really changed it was still the same and so, we asked again would they be interested in having their child assessed through early intervention just so we could kind of figure out what specifically it was that we were needing or what that child's issues were and how we could better support them. ... it was a hard conversation.

During those experiences, she felt that lack of knowledge and with that a lack of confidence-not knowing what to do, not knowing kind of information to pass on, asking herself, "Do I make a suggestion to have this child evaluated? Do I not?" The teachers interviewed all felt additional training about how to discuss concerns and seek out intervention resources to be critically important to new staff members and those teachers who are just entering the field.

Also examined was the need for professional development in inclusive curriculum and instruction, collaboration and consultation, disability specific information, and identification, referral, and resources related to inclusion. Teachers felt these aspects of professional development were critical if inclusion was to be successful.

Teacher C declared new teachers need,

Real basic training about some of the things that you might find, the kind of issues- typical issues maybe you may find and how we can use strategies. You know I think with the amount of children that come into your class in terms of 
kids with some needs special needs I would say having a larger support system and academic knowledge.

Teacher A stated,

I think it would be really great if our whole staff could have more training on working with children with special needs and not just in one area but I don't know if you can break it down into sensory are social level or something like that where you can really go into depth into each area.

With this more in-depth knowledge there could be a deeper understanding of the child's individual needs and the variety of disabilities which occur during early childhood. This particular teacher reported that if she had this type of disability specific information, she might feel more confident in identifying differences or needs seen in her classroom and seek out services sooner if needed.

Another teacher wanted the priority to be around collaboration with families and professionals. This teacher expressed a need "to have opportunities for that collaboration, to have understanding around how teachers and families come together in dialogue about the child's abilities and also with intervention specialists."

\section{Support from Administrators, Peers, Specialists, Therapists}

Across interviews, a second theme of collaboration, within the process of inclusive education, permeated the discussion. In describing an experience working with a child with special needs, a teacher related that the early intervention team that came into 
the classroom was invaluable. She really felt that they added to her experience as a teacher. The additional validation that she received from them that she was doing the right things was also a big support. This kind of support, as well as support from administrators, peers, and on-site consultants from the Graduate School of Education, and a local service district were seen as crucial aspects of being able to provide support to children with special needs in their classrooms. Within this theme the different types of support provided by administrative staff, peers, and on-site consultants was examined.

Participants noted several different kinds of supports which would be beneficial to including young children with special needs. One participant believed the supports at the top of the list had to include "adequate and appropriate staffing or else it (inclusion) is just not feasible." Another teacher added that, especially, as an urban school that takes children out into the community, additional staff are needed "when you have a child that needs more one-on-one attention." Other supports mentioned during the interviews include having a stronger system for "Identifying and then working with and developing curriculum for children with special needs; some kind of process, I don't know what it would look like but...especially if you have a really physically aggressive child...”

Two of the four teachers reported that being able to go to an administrator and openly communicate with them about concerns without judgment and with support during parent-teacher conferences was important. Teacher E expressed a belief that there should be some policy in place, "maybe some structure that would create no-fault for classroom teachers. So classroom teachers feel like that they can initiate a conversation 
with the family or families, feeling able to comfortably initiate a conversation and be backed up by an administrator."

A real strength of the center seemed to be the amount of peer support available to staff. All of the teachers interviewed that they wanted more opportunities to share their experiences. One teacher discussed how different it is at this particular center to be “among peers who are much more educated ...they don't have all the skills but then we sit down together and we're brainstorming..." Another teacher said, "Here at Helen Gordon it's different because one you're among peers who are much more educated and interested in their own ongoing education and then having the position that you had last year, the grad assistantship the masters grad assistant thing- that was really a big help too." One teacher was particularly excited about a new process called the Child Study Team. She described it hopefully stating, "I think maybe like some kind of process like that we're doing with the Child Study Team. I think that's really great in the sense of using some other or resources that we have here before automatically go into early intervention, you know, like asking other teachers and having other people observe I think it's really important." She declares that written policies are also important,

But then I think you have to have some kind of process. I don't know what that would look like but, you know, especially if you have a really physically aggressive child I think that would be important, for me, since I've never had a child in my classroom that... I've seen other teachers dealing with it you know, but for me personally, I think that that would be an area that I would want to know more information. 
Three of the four teachers interviewed felt it was crucial to add a full-time staff member with specialized training in Early Intervention/Early Childhood Special Education. There has been a graduate student in this position for the last two years and each teacher spoke of the importance of such a position. One teacher said that "having a person in your position (the graduate student position) and expertise that can support teachers who are scared to talk to parents, I think that it's really helpful." Another teacher stated that "I want someone who's outside of our classroom who doesn't already have a view of this child to come in and observe and kind of get their perspective." She also stated that before there were people who were on the administrative team who could or would come in and do observations, but she found herself asking the questions: "Who can I go to? Who do I know that will have the time? Who will have the time and is familiar with these situations?" This teacher felt this issue presented the most challenges because it may be that she found someone with experience, but it would be two weeks before they could come into the classroom. During the past two years, with the addition of a graduate student, the teachers felt this had changed.

Which I think helped...now we do kind of have that go to person who is here. It would be great if that person could be full-time. Just so that way they could know that... that's their job and they're here and can be a part of those meetings if we need them to be, they are more available for observation...I think it is essential for a center of this size and with the work that we are doing I think we would benefit so much from it. 
Within this particular theme, as reported by the participants, support provided by administrative staff, peers, and on-site consultants were examined. Teachers felt strongly about the levels of support needed from these different groups of people. While peer support seemed to be the most readily available at this particular center, support from administrators and on-site consultants with specialized training in special education was viewed as crucial for the success of inclusion in this center. It was difficult however, to determine if this insistence accurately reflected the needs of the center or if it merely reflected the needs of these particular teachers when examining their own feelings of efficacy.

\section{Experience Fosters Success}

The teachers selected for this study had some experience working in the past with a child with special needs in their classroom. When asked to share their experiences working with children with disabilities, all of the teachers expressed that the experience had made them a better teacher, was beneficial to everyone in the class, and led them to feel more confident when working with other children who had special needs. Because of these experiences, each teacher expressed positive feelings about inclusion and working with young children with disabilities. The following theme examines teacher's

experiences and their belief that having experience with children with disabilities helps to facilitate a more positive perception of inclusion.

When examining the experience of each teacher interviewed, two of the four had 15 year plus experience working in classrooms with children with special needs ("there's 
at least one every year.”). The third teacher has been teaching for ten years and noted in her interview that in the last three years there has been an increase in the number of children with special needs enrolled at the school and in her class in particular ("I've had at least one or two"). Each of these three teachers tells stories in both their journals and in their interviews of positive experiences with families and children with special needs. Many times they focused on the benefits of inclusion and minimized the challenges. One teacher reflected, "Some of it I think is just instinct I guess. I think it falls back on just being really patient and really...I think I have a calm presence.” When discussing challenges these teachers talk about how it could be challenging for new teachers, claimed,

I've always had children, since the 80 s, in classes that have shown behaviors and skills that were outside the norm that you would anticipate; Newer teachers don't seem to have, I guess, I would expect them to have more knowledge...I think it would really help if they had a stronger background on how to help people who are coming into their classrooms be successful.

She later to stated,

Newer teachers this year don't seem like they understood how we support children here at Helen Gordon CDC that have special needs, you know? Even real basic training about some of the things you might find, kind of issues typical issues you may find and how we use strategies and where to go if you don't really 
know how to use those...you're kind of sticking them in environments where they don't have any basis for knowledge.

Interestingly, the one teacher who had only recently had an experience working with a child with special needs also highlighted the benefits of inclusion and minimized the challenges. In the interview with this teacher her only challenges included knowing where to start the process of communicating with a parent when a difference in development is noted. She stated,

I feel like I can include them in the curriculum but when it comes to outside of my classroom I wonder if I'm doing enough, am I getting them the services that or could I be getting them services that they could possibly need or do they not need them.

This last theme examined teacher's experiences and their belief that having experience with children with disabilities helps to facilitate a more positive perception of inclusion. Each of the teacher's interviewed previously had experience working with children with disabilities and thus felt more positive about current and future experiences.

\section{Research Question \#2}

As you can see from the above paragraphs, many of the teachers felt that additional training, support from peers, administrators, and specialists was the most critical aspect of including a child with a disability. The data were inconclusive as to which particular support or level of support was of more value. However, it was noted that all teachers believed that having a graduate student or another professional with 
knowledge and experience in early childhood special education on staff full-time was critical if the school as a whole were to be successful in including more children with special needs. At this particular school, the blending of the graduate internship and the use of a child study team to examine the needs of children in the center seemed to be a powerful combination. There were not enough data at the time of the study to fully determine whether or not this combination had an overall positive effect on the teacher's perceptions of support or their feelings of efficacy.

\section{Research Question \#5}

In examining the influence of pedagogy on the ability of a teacher to fully include a child with a disability, this value of difference and insistence that all participants' help to co-construct knowledge sets a foundation for teachers and staff in this school to support inclusion and fully integrate this aspect of program philosophy into their teaching. The teachers interviewed believed that the differences found in their classroom across children enhanced the experiences of everyone including children, teachers, families, specialists, and the wider school community. In answering this research question, the value of difference and the philosophical underpinnings of the coconstruction of knowledge were analyzed through the statements of the teachers themselves.

The teachers felt that the inclusion of a child or children with special needs was a very important aspect of their work, and a responsibility central to their teaching. One teacher stated that inclusive classrooms are a reflection of the world around us and 
“children learn a lot and I think I learn a lot from being around people who are different from each other."

This idea of difference as a value was reflected in the other interviews as well. In one interview, a teacher described how she acknowledged difference in her classroom.

And we'd have those conversations as a whole classroom about how we're different and we all have different interests, personalities, and you know, our emotions are all different in certain situations and that we have to respect that and find ways to work together.

She remarked that in the classroom she tries to make it apparent from the beginning that,

We are a community, we are a family, and we work together... it makes that inclusion so much easier because you are already stating that process and your recognizing, you're acknowledging that everyone is different in their own way and that's great!

Another teacher with more than fifteen years of experience described a model of teaching, a round table approach, as discussed in the writings of Jerome Bruner. The teacher spoke of the value of multiple perspectives in efforts to collectively define experience, and said, "Differing contexts, unique ways of seeing, thinking, and experimenting make the experience richer for all those at the table. Everyone is of value." This teacher highlighted this point with an analogy stating, 
Each person- teacher, students, parents, communities standing together in a circle holding hands. Each person stands with competence, and yet only when we reach out to each other do we have the power that comes from forming the circle: connection, enclosure. We see the subject matter in the center from all perspectives, as well as from our own unique perspective.

Another teacher commented similarly that inclusion as an experience with everyone working together and being a part of the classroom community.

Their ideal inclusive environment would be to have all of those people (specialists, teachers, children), including the families, all working together with the children who have identified special needs, with children who could have special needs, and with children who are typically developing.

These perspectives exemplify the value of difference and the idea that all participants in the inclusive school are co-constructors of knowledge and thus important. This stretches the idea or question of inclusion beyond that of a single child or family of a child with a disability to impress upon the community of this particular school that inclusion is a value that transcends disability and explores the differences found in all of us.

This study attempted to answer questions about the supports early childhood teachers need to fully include children with disabilities in their classrooms. The research questions included: 1) What supports are needed for early childhood teachers to fully 
include children with special needs? 2) What are teacher's perceptions of support (e.g., what supports do they perceive to be most helpful and why)? 3) How does the early childhood teacher's perception of support influence their ability to feel successful in including a child with special needs? 4) How do early childhood teachers perceive successful inclusion of a child with special needs? 5) How does the program philosophy and curriculum influence teachers' ability to fully include a child with a disability?

Through the examination of interviews and journals from participants, themes were found which provided answers. A strong philosophy which places the value of difference at its core, and the co-construction of knowledge by all participants was crucial in influencing the feelings of efficacy among this group of teachers. Additionally, support from administrators, peers, on-site consultants, professional development, and experience with children with disabilities and their families produced more positive feelings about including a child with a disability in their class. Teachers felt these supports were crucial and indicated that all new teachers, whether in pre-service or through in-service should have access to these supports and be provided information about the benefits and positive experiences of others who have included a child with a disability into their classroom 


\section{Chapter 5: Discussion}

The purpose of this study was to examine the needed supports for full inclusion of children with special needs at a university-based preschool and the teacher's perceptions of those supports. The results indicated that to successfully include a child with special needs, teachers need support from administrators, peers, and consultants, additional training, positive experiences, and a strong philosophical and curricular base which values differences among individuals.

\section{Attitudes and Philosophy of the Program}

Throughout the interviews there was a consistent theme that, within this particular setting, differences are valued and helped to construct the experiences of the group. The dominant philosophy and curriculum are consistent with this mindset. In many of the statements, teachers acknowledged that the challenges these differences bring to the experience have brought them more aware and intentional in planning activities and experiences for all of the children in the classroom. The findings in this study are consistent with current knowledge that positive attitudes and openness is a critical element in the success of inclusive classroom (Cross, Traub, Hutter-Pishgahi, \& Shelton, 2004; Dinnebell, et.al., 1998; Lieber, et al., 2000; Odom, 2000).

Currently, there are a limited amount of studies that address the importance of curriculum and program philosophy, and its impact on inclusion of children with disabilities in early childhood settings. However, one can infer that the value of difference, image of the child, and constructivist pedagogy of the schools in Reggio 
Emilia have had some influence on success of children with disabilities (Edwards, et al.,1993; Gandini \& Kaminsky, 1993). Programs looking to improve their feelings of success and demonstrate a willingness to serve children with disabilities should assess whether or not their program philosophy and attitudes of their staff are congruent with Anti-Bias Curriculum, and the approach to education of municipal preschools in Reggio Emilia, Italy.

\section{Additional Training}

One of the most cited barriers to inclusion in early childhood is lack of sufficient training in pre-service or in-service training (Bricker, 2000; Mulvilhill, et al., 2002; Soodak, et al., 2002; Wolery \& Odom, 2000; Wolery \& Wilbers, 1994). Consistent with research, the teachers in this study reported feeling underprepared to serve children with disabilities in their classrooms. These feelings occurred despite the teachers having high level education in their field (Bachelor's degree or higher). The pre-service programs the teachers described had one limited class on working with children with disabilities. Many of the teachers, feeling underprepared, sought information or training on their own and tried to piece meal it together when presented with challenges in their classroom. The teachers believed that if they had training ahead of time, their initial experiences with children with special needs would have been less challenging and more positive overall.

The teachers thought that it would enhance the program if topics around disability, consultation and collaboration, and embedded instruction were a part of required trainings for new staff and offered as continuing training for existing staff. 
Evidence shows that consistent and ongoing training in these topics has a dramatic effect of feelings of efficacy among teachers in inclusive classrooms (Buysee \& Wesley, 2004; Dinnebell, et al., 1998). This center is in the unique position of being located within a university setting with an early childhood special education program and has an established relationship with professionals who provide special education services to young children with disabilities countywide. Having access to professionals within the field of special education would allow for increased opportunities for ongoing professional development. Additionally, opportunities exist for collaborative crosstraining endeavors around program philosophy and curriculum and its influence or impact on children with special rights.

\section{Administrative, Peer, and Consultant Support}

In many studies, administrative support was also viewed as critical for the successful inclusion of a child with a disability (Dinnebeil, et al., 1998; Leatherman, 2007; Leiber, et al., 2000; Odom, 2000; Villa \& Thousand, 2003, Wolery \& Odom, 2000; Wood \& Youcha, 2009). Though there is not much research on the impact of peer support, there are studies, which suggest that the impact of itinerant teacher consultants is significant, and that consultants are one of the supports necessary for successful inclusion in early childhood settings (Buysee \& Wesley, 2004; Dinnebeil, et al., 1998). Responses provided in this study are consistent with research in suggesting that providing additional staffing, policies and procedures, guidance, and on-site consultation are necessary to support teachers who include a child with a disability in their classroom. 
Many of the teachers noted the current policies were not clear and that they often did not know where to turn when they suspected a child may not be meeting developmental milestones. They were hopeful, however, that new practices including the addition of a graduate student from the University's Department of Special Education and the creation of a child study team were being established to support the teachers, staff, and students in the school. These collaborative efforts, with strong leadership from administrators, will provide support for teachers of varying experiences as the center becomes more fully inclusive of children with disabilities.

\section{Limitations and Future Research}

The results of this study have implications with regards to supports needed in inclusive early childhood settings; however, there are some limitations to consider. One such limitation is that while there were protections put in place by the researcher (i.e., data from a variety of sources and member checks), the relationship of the researcher to those interviewed may have supported biased results. The interviewees all had an existing relationship both professionally and personally with the researcher. It is possible that their knowledge of the researcher's own value of inclusive education may have influenced their answers or led them to provide answers that they felt would please the researcher. In future research, additional protections against bias such as having an interviewer who has no relationship to the participants may be needed.

A second limitation is that the interviews and journals were viewed in isolation; no other measures were used to determine needs, measure efficacy, or further examine 
their experiences in the inclusive classroom. A third limitation, supposes that a richer, more detailed description could have been obtained if additional follow-up interviews had been conducted. Finally, while discussion with an outside party regarding the coding of the themes took place, no outside party reviewed the information from journals or interviews to determine consensus. In future research, a more thorough peer debriefing should take place to ensure validity of themes.

Further examination of other early childhood philosophical practices and the influence on quality inclusive practices should be attempted in the future. Additionally, information gathered from a more diverse group of teachers (e.g., variance across experience, education, and position) of teachers would be useful in determining the varying needs of early childhood teachers who fully include children with special needs in their classroom.

\section{Recommendations}

For this particular setting and other early care and education settings looking to improve practices for fully including children with disabilities, the researcher would propose that centers initially assess whether or not the program philosophy and attitudes of their staff are congruent with those found in the schools of Reggio Emilia and encourage the use of Anti-Bias Curriculum. As demonstrated in this study, the overarching value of difference found in the Reggio Approach and within Anti-Bias Curriculum provided a foundation for including children with special needs. In-service training and follow-up support from administrators would ensure that all staff at the 
center share a common understanding of the different components of the program and can demonstrate this in the classroom setting. Cross-training with members of partnering agencies that provide special education services and the other departments at the University that work in the school should also be considered to ensure a common understanding of program philosophy and curriculum.

With regards to professional development, provide teachers and staff with inservice topics around disability, consultation and collaboration, and embedded instruction. These topics were viewed by the teachers in this study as critical in establishing a framework for understanding the needs of young children with disabilities and changing expectations which may arise as the center becomes more inclusive. Trainings should be required for new staff and offered as continuing professional development opportunities for existing staff. These trainings would be excellent opportunities to strengthen the partnerships with outside agencies that provide special education services and the other departments at the University. These entities may provide trainings at a free or reduced cost to the program.

The development of clear policies and procedures around inclusion are necessary for programs that include children with disabilities. Assess written policies and procedures around developmental assessments, referral of children for special education services, the responsibilities of staff in discussing concerns with parents, expectations around implementing Individualized Family Service Plans (IFSP) within the classroom, and participation in intervention teams is necessary to ensure common understanding for 
both parents and staff. These policies should be congruent with current laws which protect the rights of children with disabilities and their families.

\section{Conclusion}

Inclusion in early childhood settings remains a goal for many early care and education centers and professionals. Despite a growing body of research on this subject matter, and recommended practices which promote inclusion, professionals are still grappling with the challenges, and barriers to inclusion for young children (Bricker, 2000; Mulhivill, et al., 2002; Leiber, et al, 2000; Odom, 2000; Purcell, Horn, \& Palmer, 2007). The experiences, knowledge, and support early childhood professionals receive when fully including a child with special needs is critical to the success of inclusion for all who are involved.

As the population of children in early care and education settings becomes more diverse, the needs of these children become more challenging for teachers to address. Early childhood educators are thirsty for knowledge and support as they include children with disabilities in their classrooms. Pre-service professional programs must engage professionals more with regards to what they need to be successful in the field. More cross-discipline training is imperative, as is cross-discipline collaboration for inclusion to be successful (Buysee \& Wesley, 2004; Mulvihill, et al., 2002; Odom, 2000; Soodak, et al., 2002). This particular university-based preschool has an advantage and is already moving forward to improve inclusive practices in their own community. Hopefully, in 
further research and activities at this center, information can be gathered regarding the effectiveness of those practices. 


\section{References}

Bailey, D., McWilliam, R., Buysee, V., \& Wesley, P. (1998). Inclusion in the context of competing values in early childhood education. Early Childhood Research Quarterly, 13(1), 27-47.

Bricker, D. (1978). Early intervention: the criteria of success in early intervention with infants and young children. Allied Health and Behavioral Sciences Journal, 1, $567-582$.

Bricker, D. (2000). Inclusion: how the scene has changed. Topics in Early Childhood Special Education, 20(1), 14-19.

Bricker, D., \& Bricker, W. (1971). Toddler research and intervention project report: year I. IMRID Behavioral Science Monograph No. 21. Nashville: George Peabody College Institute on Mental Retardation and Intellectual Development.

Brown, W., Odom, S., Li, S., \& Zercher, C. (1999). Ecobehavioral assessment in early childhood programs: a portrait of preschool inclusion. The Journal of Special Education, 33(3), 138-153.

Buysse, V., \& Wesley, P. (2004). A framework for understanding the consultation process: stage-by-stage. Young Exceptional Children, 7 (2), 2-9.

Capper, C. A., Frattura, E., \& Keyes, M. A. (2000). Meeting the need of student of all abilities: how leaders go beyond inclusion. Thousand Oaks, CA: Corwin. 
Cross, A., Traub, E., Hutter-Pishgahi, L., \& Shelton, G. (2004). Elements of successful inclusion for children with significant disabilities. Topics in Early Childhood Special Education, 24(3), 169-183.

Derman-Sparks, L. (1989). Anti-bias curriculum: tools for empowering young children. Washington, DC: National Association for the Education of Young Children.

Derman-Sparks, L. \& Edwards, J. (2010). Anti-bias education for young children and ourselves. Washington, DC: National Association for the Education of Young Children.

Dinnebell, L., McInerney, W., \& Fox, C. (1998). An analysis of the perceptions and characteristics of childcare personnel regarding inclusion of young children with special needs in community-based programs. Topics in Early Childhood Special Education, 18(2), 118-28. Retrieved from Wilson Web.

Division of Early Childhood \& the National Association for the Education of Young Children (2009). Early Childhood Inclusion. A Joint Position Statement of the Division of Early Childhood (DEC) and the National Association for the Education of Young Children (NAEYC). Retrieved from http://www.decsped.org/uploads/docs/about_dec/position_concept_papers/PositionStatement_Inc lusion_Joint_updated_May2009.pdf.

Edwards, C., Gandini, L. and Forman, G., (Eds.). (1998). The Hundred Languages of Children: The Reggio Emilia Approach-Advanced Reflections (2nd Ed.). Greenwich, CT: Ablex. 
Edwards, C., Gandini, L., \& Forman, G. (Eds.). (1993). The Hundred Languages of Children: The Reggio Emilia Approach to Early Childhood Education. Norwood, NJ: Ablex.

Gandini, L. \& Kaminsky, J. (2006). To know a child with special rights: an interview with Ivana Soncini. Innovations in early education: the international Reggio exchange 13(1). Wayne State University.

Gargulio, R. and Kilgo, J. (2005). Young children with special needs ( $2^{\text {nd }}$ ed). NJ: Pearson

Gargiulo, R., Sluder, L., \& Streitenberger, D. (1997). Preparing early childhood educators for inclusive programs: a call for professional unification. Early Childhood Education Journal, 25(2), 137-39.

Gay, L. R., Mills, G. \& Airasian, P. W. (2009). Educational research: competencies for analysis and interpretation. (9th ed.). NJ: Pearson.

Guralnick, M. J. (Ed.) (1978). Early intervention and the integration of handicapped and nonhandicapped children. Baltimore: University Park Press.

Guralnick, M. (2001) Inclusion as a core principle in the early intervention system. In M.J. Guralnick (ed.) Early Childhood Inclusion: Focus on Change, (p.60-66).

Helen Gordon Child Development Center (2008). Guidelines for Infant Wing. Portland State University, Portland, OR. 
Katz, L. (1993). What can we learn from Reggio Emilia? In C. Edwards, L. Gandini, \& G. Forman (Eds.), The Hundred Languages of Children: The Reggio Emilia Approach to Early Childhood Education. Norwood, NJ: Ablex.

Katz, L. (1998). What can we learn from Reggio Emilia? In C. Edwards, L. Gandini, \& G. Forman (Eds.), The Hundred Languages of Children: The Reggio Emilia Approach to Early Childhood Education (2 ${ }^{\text {nd }}$ ed.). Norwood, NJ: Ablex.

Kavale, K. (2002). Mainstreaming to full inclusion: from orthogenesis to pathogenesis of an idea. International Journal of Disability, Development, and Education, 49(2). Retrieved from Academic Search Premier.

Leatherman, J. (2007). “I just see all children as children”: teachers' perceptions about inclusion. The Quarterly Report, 12(4), 594-611.

Leiber, J., Capell, K., Sandall, S., Wolfberg, P., Horn, E., \& Beckman, P. (1998). Inclusive preschool programs: teachers' beliefs and practices. Early Childhood Quarterly, 13, 87-106. Retrieved from Science Direct.

Lieber, J., Hanson, M., Beckman, P., Odom, S., Sandall, S., Schwartz, I., ... Wolery, R. (2000). Key influences on the initiation and implementation of inclusive preschool programs. Exceptional Children, 67 (1), 83-98. Retrieved from Wilson Web.

Meisels, S. J. \& Shonkoff, J. P. (2000). Early childhood intervention: A continuing evolution. In J. P. Shonkoff \& S. J. Meisels (Eds.), Handbook of early childhood intervention (second edition, pp. 3-31). New York: Cambridge University Press. 
Mulvihill, B., Shearer, M., \& Van Horn, M. (2002). Training, experience, and childcare providers' perceptions of inclusion. Early Childhood Research Quarterly, 17, 197-215.

National Association of Childcare Resource and Referral Agencies (NACCRRA) (2009). Number of children potentially needing care. Retrieved from http://www.naccrra.org/randd/docs/Children_Potentially_Needing_Care.pdf

National Center for Education Statistics (NCES) (2006). Enrollment in early childhood education programs. Retrieved from http://nces.ed.gov/pubs/eiip/eiipid02.asp.

National Dissemination Center for Children with Disabilities (1995, June). Planning for inclusion. News Digest v5 (1). Retrieved from http://www.nichcy.org/informationresources/documents/nichcy\%20pubs/nd24.pdf

North American Reggio Emilia Alliance (NAREA). Membership coordinators list. Retrieved May 15, 2010 from http://www.reggioalliance.org/narea/communication_and_networking/membershi p_coordinators/current.php.

Odom, S. (2000). Preschool inclusion: what we know and where we go from here. Topics in Early Childhood Special Education, 20(1), 20-27.

Odom, S. (2002). Widening the circle: including children with disabilities in preschool programs. New York: Teachers College Press. 
Odom, S., Hanson, M., Lieber, J., Marquart, J., Sandall, S, Wolery, R.,...Chambers, J. (2001). The costs of preschool inclusion. Topics in Early Childhood Special Education, 21(1), 46-55.

Odom, S. L., \& Schwartz, I. S. (2002). So what do we know from all this? synthesis points of research on preschool inclusion. In S. L. Odom (Ed.), Widening the circle: including children with disabilities in preschool programs (pp. 154-174). New York: Teachers College Press.

Patton, M. Q. (2002). Qualitative evaluation and research methods (3rd ed.). Thousand Oaks, CA: Sage Publications.

Purcell, M., Horn, E., \& Palmer, S. (2007). A qualitative study of the initiation and continuation of preschool inclusion programs. Exceptional Children, 74(1), p8599.

Riehl, C. (2000). The principal's role in creating inclusive schools for diverse students: a review of normative, empirical, and critical literature on the practice of education administration. Review of Educational Research, 70(1), 55-81.

Ryndak, D., Jackson, L., \& Billingsly, F. (2000). Defining school inclusion for students with moderate to severe disabilities: what do experts say? Exceptionality, 8(2), p101-116. Retrieved from Academic Search Premiere on July 31, 2009.

Sapon-Shevin, M. (2003). Inclusion: a matter of social justice. Educational Leadership, 61(2), 25-29. 
Smith, C. (1998). Children with" special rights" in the preprimary schools and infanttoddler centers of Reggio Emilia. In C. Edwards, L. Gandini, \& G. Forman (Eds.). The Hundred Languages of Children: The Reggio Emilia Approach to Early Childhood Education. Norwood, NJ: Ablex.

Smith, M., \& Diugosh, L. (1999). Early childhood classroom teachers' perceptions of successful inclusion: A multiple case study. Paper presented at the Annual Conference of the American Educational Research Association, Montreal, Quebec, Canada.

Smith, M., \& Smith, K. (2000). “I Believe In Inclusion, but...”: regular education early childhood teachers' perceptions of successful inclusion. Journal of Research in Childhood Education, 14(4), 161-80.

Soodak, L., Erwin, E., Winton, P., Brotherson, M., Turnbull, A., Hanson, M., \& Brault, L. (2002). Implementing inclusive early childhood education: a call for professional empowerment. Topics in Early Childhood Special Education, 22(2), 91-102.

Stainback, S., Stainback, W., \& Forest, M. (Eds.). (1989). Educating all students in the mainstream of regular education. Baltimore: Brookes.

Strain, P. (1990) Least restrictive environment (LRE) for preschool children with disabilities: what we know, and what we should be doing. Journal of Early Intervention, 14(4). 
Thompson, N. (2006). She is our little sister: reflections about inclusion. Innovations in Early Education: the International Reggio Exchange 13(1).Wayne State University.

United States Census Bureau (2010, August). Who's minding the kids? child care arrangements: spring 2005/summer 2006. Retrieved from http://www.census.gov/prod/2010pubs/p70-121.pdf

United States Congress, (1968). Public Law 90-538: handicapped children's early education assistance act.

United States Congress (1972). Public Law 92-424: economic opportunity amendments.

United States Congress (1973). Rehabilitation act.

United States Congress (1975). Public Law 94-142, the education for all handicapped children act.

United States Congress (1986). Public Law 99-457, the education of the handicapped act amendments.

United States Congress (1990). Public Law 101-476, individuals with disabilities education act (IDEA).

United States Congress (1997). Public Law 105-17, IDEA reauthorization.

United States Congress (2004). Public Law 108-446, the individuals with disabilities Education improvement act (IDEIA). 
United States Department of Education (2007). Office of Special Education Programs' $29^{\text {th }}$ Annual Report of the Implementation of the Individuals with Disabilities Act, volume 1. Retrieved from http://www2.ed.gov/about/reports/annual/osep/2007/parts-b-c/29th-vol-1.pdf.

Pikler.org (No Date). Pikler principles. Retrieved from http://pikler.org/PiklerPractices.html

RIE.org (no date). RIE Approach. Retrieved from www.rie.org.

Van Horn, G., Burrello, L., \& DeClue, L. (1992). An instructional leadership framework: The principal's leadership role in special education. Special Education Leadership Review, 1(1), 41-54.

Villa, R. \& Thousand, J. (2003). Making inclusive education work. Educational Leadership, v61 (2), p.19-23. Retrieved from Academic Search Premier.

Voltz, D., Brazil,N., \& Ford,A. (2001). What matters most in inclusive education: a practical guide for moving forward. Intervention in School and Clinic, 37(1), p2330.

Wolery, M., \& Wilburs, J.S. (1994). Introduction to the inclusion of young children with special needs in early childhood programs. In M. Wolery \& J.S. Wilbers (Eds.), Including children with special needs in early childhood programs (pp. 1-22). Washington, DC: National Association for the Education of Young Children. 
Wolery, R. A. \& Odom S. L. (2000). Administrator's guide to preschool inclusion. University of North Carolina: Early Childhood Research Institute on Inclusion.

Wong, S. \& Cumming, T. (2010). Family day care is for normal kids: facilitators and barriers to the inclusion of children with disabilities in family day care. Australaisian Journal of Early Childhood; Vol. 35 (3), p4-12.

Wingert \& Kantrowitz, 1991. The Best Schools in the World. Newsweek. Retrieved from http://www.newsweek.com/1991/12/01/the-best-schools-in-the-world.html.

Wood, K. \& Youcha, V. (2009). The abcs of the ADA: your early childhood program's guide to the americans with disabilities act. Baltimore: Brookes. 


\section{Appendix A: Demographic Information}

Please fill out the following information and return to the mailbox of Meredith Villines at Helen Gordon Child Development Center.

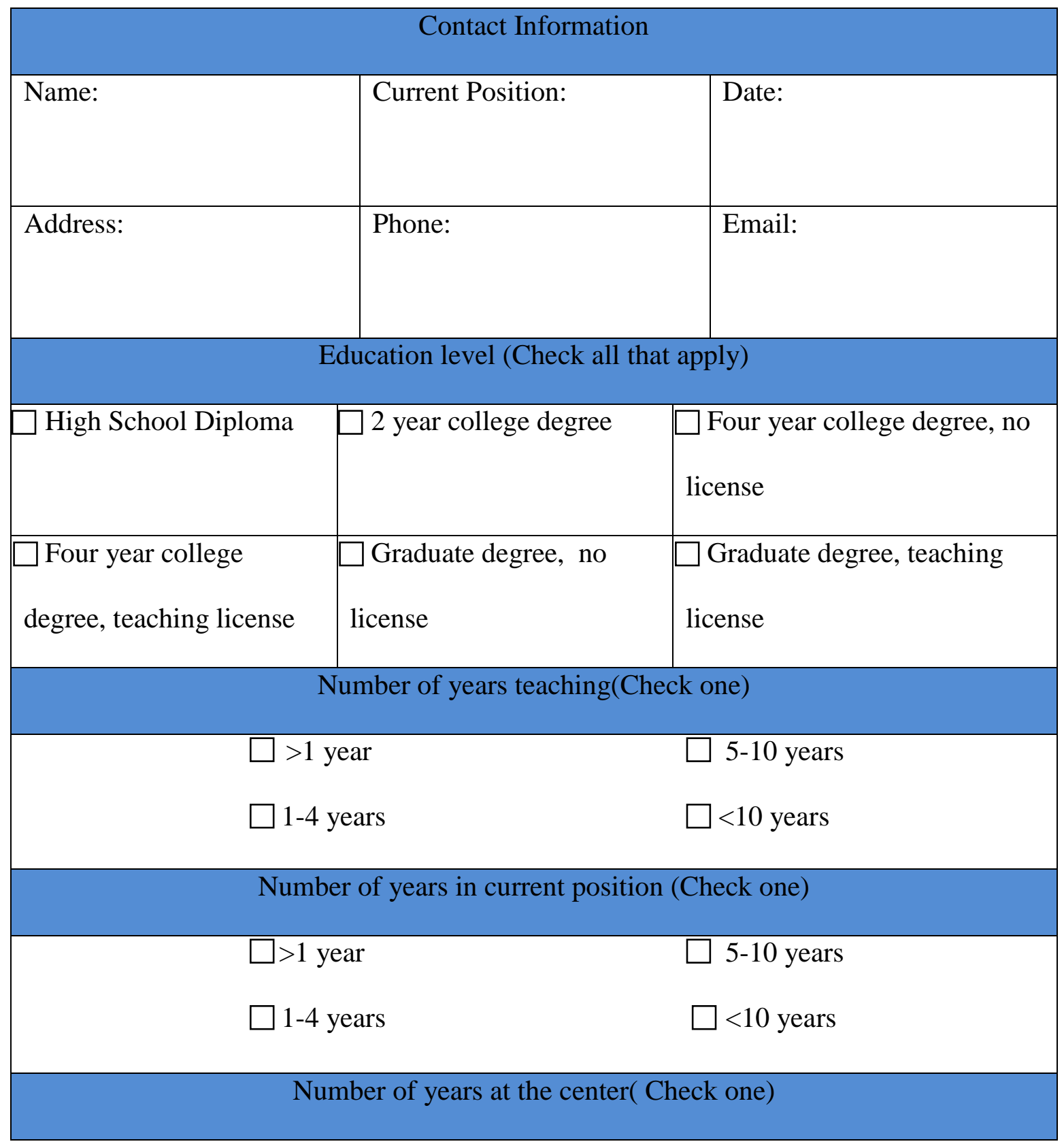




\begin{tabular}{|l|}
\hline \multicolumn{1}{|c|}{$\square>1$ year } \\
$\qquad 1$ 1-4 years \\
Do you have experience with children with special needs? _ yes _ no \\
If yes, is the child currently a student in your classroom? _ yes _ no \\
In the last year, have you sought the support of the graduate assistant from the special \\
education department?
\end{tabular}




\section{Appendix B: Human Subjects Letter for Participants}

Early Childhood Inclusion: Teacher Perception of the Supports Needed to Fully Include Children with Special Needs

You are invited to participate in a research study conducted by Meredith Villines, from Portland State University, Department of Special Education. The researcher hopes to learn what supports early childhood teachers need in order to fully include children with special needs. The study is being conducted at Helen Gordon Child Development Center under supervision of David Allen, an Early Intervention/Early Childhood Special Education faculty member in the Department of Special Education. This study is in partial fulfillment of the requirements for a Master's Degree in Special Education.

You were selected as a possible participant in this study because you are currently a teacher at Helen Gordon Child Development Center and have had current or previous experience working in classrooms with children who have special needs.

If you decide to participate, you will be asked to complete a demographic information form, participate in two audio-recorded interviews, lasting approximately one to two hours, keep a journal in which you will be asked to reflect on your experiences, and consent to release information about your professional development activities over the last two years. The purpose of these activities is to obtain an in-depth look at your overall experience as a teacher in an inclusive school, and to better understand what support is needed for teachers to fully include children with special needs in the early childhood classroom. All activities will take place within the center during working hours. 
While participating in this study, it is possible that you will be asked to take time away from your classroom, and/or planning time. Efforts will be made to ensure coverage for your classroom, and/or negotiate a different schedule for planning if needed.

Additionally, if times within your typical work hours are not convenient to you, then the researcher will make arrangements to reschedule outside of working hours, at your convenience.

You may not receive any direct benefit from taking part in this study, but the study may help to increase knowledge about what supports are needed for teachers to fully include children with disabilities in early childhood classrooms, which may help others in the future. Any information that is obtained in connection with this study and that can be linked to you or identify you will be kept confidential. This information will be kept confidential by replacing your name with a code (e.g. Teacher A, Teacher B, etc.), and by maintaining documents related to the study in a locked file at all times.

Your participation is voluntary. You do not have to take part in this study, and it will not affect your position at Helen Gordon Child Development Center or your relationship with the Department of Special Education. You may also withdraw from this study at any time without affecting your position at Helen Gordon Child Development Center or your relationship with the Department of Special Education.

If you have concerns or problems related to your participation in this study or your rights as a research subject, please contact the Human Subjects Research Review Committee, Office of Research and Sponsored Projects, 600 Unitus Bldg., Portland State University, (503) 725-4288 / 1-877-480-4400. If you have questions about the study itself, contact Meredith Villines at meredith_villines@yahoo.com, (919) 260-0877, or 
David Allen, Assistant Professor, Department of Special Education, Portland State University at drallen@pdx.edu, 503-725-5490.

Your signature indicates that you have read and understand the above information and agree to take part in this study. Please understand that you may withdraw your consent at any time without penalty, and that, by signing, you are not waiving any legal claims, rights or remedies. The researcher will provide you with a copy of this form for your own records.

(Name) (date) 


\section{Appendix C: Semi-Structured Interview Guide}

Early Childhood Inclusion: Teacher Perception of the Supports Needed to Fully Include Children with Special Needs

\section{Background Information}

1. Tell me a little about yourself?

2. What made you want to become a teacher?

3. How would you describe your philosophy of teaching?

\section{Ideas about Inclusion}

1. How would you define inclusion?

2. What are your beliefs about including children with special needs?

3. What does inclusion look like at this school?

\section{Experience with Children with Special Needs}

1. Tell me about your experience with children with special needs?

2. Successes?

3. Challenges?

\section{Perception of Needed Supports}

1. What do you feel necessary in order to fully include children with special needs?

2. What supports have benefited you in the past?

3. How have these supports been delivered? 


\section{Appendix D: Reflective Journal}

Early Childhood Inclusion: Teacher Perception of the Supports Needed to Fully Include Children with Special Needs

As a part of this study, you will be asked to keep a weekly journal to reflect on your experiences and thoughts about inclusion. These reflections will add to the information gathered through interviews and other sources. It is not required that you answer every question. The following questions are merely to guide your reflections. The researcher will collect the journals at the end of the study.

What are the benefits of inclusion?

What needs to be in place for inclusion to be successful?

What strategies have been helpful to you in fostering relationships between children with and without disabilities?

How does your classroom support all children?

When you need support who do you turn to?

In what ways does the philosophy of the school support inclusion?

How would you improve supports for children with special needs at this school?

How have you dealt with any challenges related to including a child with special needs?

What supports to you need to be a successful, effective teacher? 